\title{
Calcified Mesenteric Cyst- An Unusual Presentation as Strangulated Umbilical Hernia
}

\author{
${ }^{1}$ Pattankar VL, ${ }^{2}$ Roohi S, ${ }^{3}$ Mandakini BT, ${ }^{4}$ Sasturkar CJ, ${ }^{5}$ Badsheshi A \\ Dr. VL Pattankar ${ }^{1}$, Professor and Head*, Dr. Shagufta Roohi ${ }^{2}$, Assistant Professor*, Dr. Mandakini BT ${ }^{3}$, Associate Professor*, \\ Dr. Sasturkar $\mathrm{CJ}^{4}$, Chief Pathologist ${ }^{\mathrm{x}}$, Dr. Arunkumar Badsheshi ${ }^{5}$, Consultant Surgeon ${ }^{\mathrm{x}}$, \\ *From Department of Pathology, Khaja Bandanawaz Institute of Medical Sciences (KBIMS), Gulbarga, India \\ xDhanvantari Hospital associated with Khaja Bandanawaz Institute of Medical Sciences (KBIMS), Gulbarga, India
}

Address for correspondence: Dr Shagufta Roohi, Email: shaguftaroohi@yahoo.com

\begin{abstract}
Mesenteric cysts are usually incidental findings during laparotomy. Calcified Mesenteric cyst presenting as irreducible umbilical hernia is a very rare presentation. Hereby we are presenting such a case for its rarity.
\end{abstract}

Keywords: Mesenteric Cyst, Hernia, Calcification.

\section{Introduction}

Mesenteric cysts are rare intra-abdominal pathologies without typical clinical findings. It has been reported that the mesenteric cysts have an incidence of $1 / 100000$ hospital admissions in adults and 1/20000 in children ${ }^{1,2}$.

They are usually incidentally found at laparotomy. The symptoms vary from acute abdominal signs to non-specific abdominal findings. Mesenteric cysts can be located anywhere in the mesentery from the duodenum to the rectum $^{1,2}$. To our knowledge, only eight cases, of which six have been located in an inguinal hernia, and one in femoral hernia, have been reported in the literature and a single case of complicated mesenteric cyst located in an irreducible umbilical hernial sac has been reported ${ }^{3,4,5,6}$. Further calcification of the mesenteric cyst is a feature which has not been reported so far. We are reporting a case of calcified mesenteric cyst presenting as irreducible umbilical hernia which is very rare.

Manuscript received: $11^{\text {th }}$ Aug 2013

Reviewed: $16^{\text {th }}$ Aug 2013

Author Corrected: $19^{\text {th }}$ Sep 2013

Accepted for Publication: 20 $0^{\text {th }}$ Sep 2013

\section{Case Report}

A 50 years male presented with sudden onset of severe abdominal pain in umbilical region since 2 days. There was history of swelling in umbilical region for one year, which aggravated on coughing. The abdominal examination revealed mild abdominal distension and lump found in umbilical region that was irreducible, firm in consistency and was tender.

With the diagnosis of acute abdomen, an urgent laparotomy was performed. A $2 \mathrm{~cm}$ diameter mesenteric cyst originating from the mesentery of the transverse colon was found in the hernial sac. Exploration revealed minimal reactive intra-abdominal fluid and oedematous small intestines.

The cyst was carefully and easily removed without resecting the bowel. Macroscopic examination showed a 2 $\mathrm{cm}$ diameter, thin-walled, hard egg-shell like and ovoid cyst. The inner surface of the cyst was smooth and unilocular. (Figure.1) 


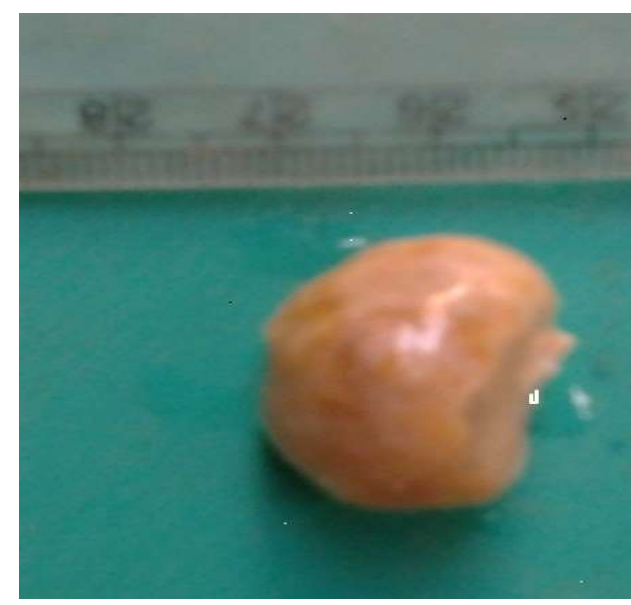

Figure 1: Gross photograph exhibiting the thin-walled, hard egg-shell like ovoid, unilocular cyst

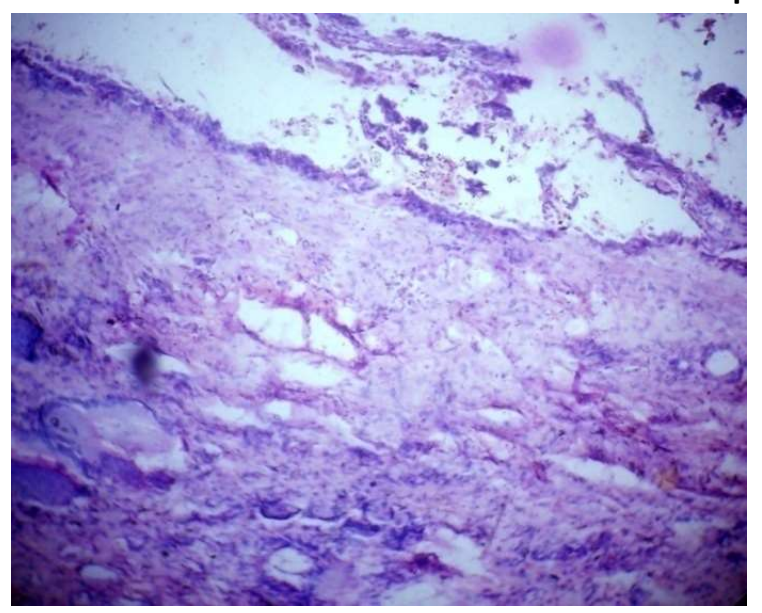

Figure 2: Microphograph showing cyst wall lined by flattened to cuboidal epithelium, at places showing papillary folds, fibrocollagenous tissue with no muscular layer and large plaques of calcification. (H\&E 100X)

Microscopically, the cyst wall was lined by flattened to cuboidal epithelium, at places showing papillary folds, with no muscular layer. It contained fibrocollagenous, fibroadipose tissue infiltrated with chronic inflammatory cells, blood vessels, and large plaques of calcification. (Figure.2)

Postoperative course was uneventful and till date there is no complaint in follow up of 6 months.

\section{Discussion}

Mesenteric cyst was first recorded in an autopsy by Florentine anatomist Beneviene in 1507, subsequently, less than 1000 have been described in the literature. Beahrs et $\mathrm{al}^{7}$. classified cystic disease of mesentery into four categories (1) Embryonic and developmental cyst (2) Traumatic or acquired cyst (3) Neoplastic cyst (4) infective or degenerative cyst. Most accepted theory of development of mesenteric cyst is benign proliferation of ectopic lymphatics in the mesentry that lack communication with remainder of the lymphatic system.

The first successful resection of a mesenteric cyst was performed by Tillaux in 1880 and successful marsupialisation of a mesenteric cyst was reported by Pean $^{2,8}$ in 1883. Subsequently, less than 1000 have been described in the literature ${ }^{9}$.

The etiology of these cysts still remains unclear. It is often discussed that they are a result of degeneration of mesenteric lymphatics, or a congenital anomaly. However, they may also result from a number of etiologies, including previous pelvic surgery, trauma, pelvic inflammatory disease, endometriosis, or neoplasia ${ }^{9}$.

Mesenteric cysts are most commonly located in the mesentery of the small intestine, usually that of the mesentery of the ileum but they can be seen anywhere from the duodenum to the rectal mesentery ${ }^{4}$.

Most cases are usually asymptomatic and detected incidentally unless complicated. They may cause nonspecific symptoms such as abdominal pain, nausea, vomiting, weakness, weight loss, diarrhoea, constipation, cramps and anorexia rarely. Symptoms due to mesenteric cysts are related to size and localization of the lesion. They usually become symptomatic when complications such as torsion, haemorrhage, infection, rupture, malignancy occur. Mesenteric cysts with more than $5 \mathrm{~cm}$ in diameter are usually symptomatic. Malignant transformation is 
rather rare and only four cases have been reported in the literature ${ }^{4}$.

Mesenteric cyst is known for recurrence if incomplete excision is done ${ }^{5}$. Therefore complete excision is treatment of choice which was possible in this case. It should be noted that with cysts that are adherent, it may be necessary to remove part of the mesentery with the mass.

\section{Conclusion}

Although mesenteric cysts are rare intra-abdominal lesions, they should be kept in mind. Because of their recurrence and malignant transformation, complete excision is mandatory.

Funding: Nil

Conflict of interest: Nil

Permission from IRB: Yes

\section{References}

1. Vanek VW, Phillips AK. Retroperitoneal, mesenteric and omental cysts. Arch Surg. 1984 Jul;119(7):838-42.

2. De Perrrot M, Brundler MA, Totsch M, Mentha G. Mesenteric cysts. Towards less confusion ? Dig Surg. 2000;17(4):323-8.
3.Mohanty SK, Bal RK, Maudar KK. Mesenteric cyst - an unusual presentation. J Pediatr Surg 1998 May;33(5): 792-3

4. Polat C, Tokyol C, Dilek ON. Strangulated umbilical hernia including a mesenteric cyst: a rare cause of acute abdomen. Acta Chir Belg. 2003;103(3):329-31.

5. Obaidah A, Shivaji B, Mane, Dhende N, Acharya H, Thakur A, Arlikar J, Reddy S. Mesentric Cyst- An Unusual Presentation as Inguinal Hernia. Indian J Surg. 2012 Mar 74(2):184-185.

6. Dellaportas D, Polymeneas G, Dastamani C, KairiVasilatou E, Papaconstantinou I. Strangulated Femoral Hernia Turned to Be Peritoneal Cyst. Case Reports in Surg, 2012, Article ID 528780.

7. Gross RE. The surgery of infancy and childhood. WB Saunders Co, Philadelphia, 1953; p377-383.

8. Kurtz RJ, Heimann TM, Holt J, Beck AR. Mesenteric and retroperitoneal cysts. Ann Surg. 1986 Jan;203(1):10912

9. Jain V, Demuro JP, Geller M, Selbs E, Romero C. A Case of Laparoscopic Mesenteric Cyst Excision. Case Rep Surg. 2012;2012:594095

\section{How to cite this article?}

Pattankar VL, Roohi Shagufta, Mandakini BT, Sasturkar CJ, Badsheshi Calcified Mesenteric Cyst- An Unusual Presentation as Strangulated Umbilical Hernia. Int J Med Res Rev 2013;1(4):209-211. doi: 10.17511/ijmrr.2013.i04.09 